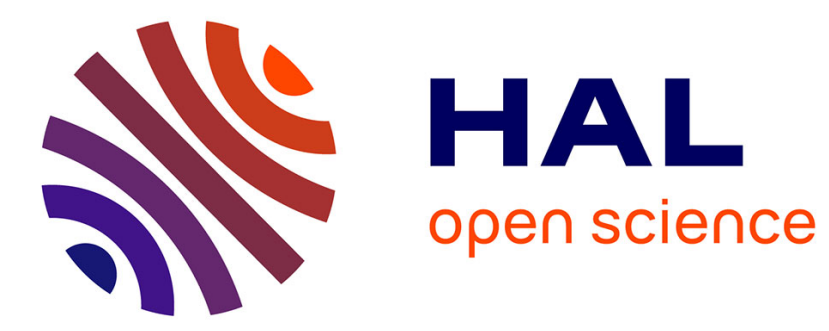

\title{
Field effect transistor with integrated microfluidic channel as pH sensor
}

\author{
Ismaïl Bouhadda, Olivier de Sagazan, France Le Bihan
}

\section{To cite this version:}

Ismail Bouhadda, Olivier de Sagazan, France Le Bihan. Field effect transistor with integrated microfluidic channel as pH sensor. Microsystem Technologies, 2015, 21 (1), pp.289-294. 10.1007/s00542014-2125-8 . hal-01066962

\section{HAL Id: hal-01066962 https://hal.science/hal-01066962}

Submitted on 22 Sep 2014

HAL is a multi-disciplinary open access archive for the deposit and dissemination of scientific research documents, whether they are published or not. The documents may come from teaching and research institutions in France or abroad, or from public or private research centers.
L'archive ouverte pluridisciplinaire HAL, est destinée au dépôt et à la diffusion de documents scientifiques de niveau recherche, publiés ou non, émanant des établissements d'enseignement et de recherche français ou étrangers, des laboratoires publics ou privés. 


\title{
FIELD EFFECT TRANSISTOR WITH INTEGRATED MICROFLUIDIC CHANNEL AS PH SENSOR
}

\author{
I. Bouhadda,O. De Sagazan, F. Le Bihan
}

IETR, university of Rennes 1

\author{
Corresponding author: F. Le Bihan, IETR, university of Rennes 1, 35000 France \\ tel: +33-2-23-23-56-91; Fax: +33-2-23-23-5657; E-mail: france.lebihan@univ-rennes1.fr
}

\begin{abstract}
This paper presents an original design of chemical sensors with an integrated microfluidic channel. Targeted applications are $\mathrm{pH}$-meters devices. The integration of the microfluidic channel allows decreasing the volume required for each measurement. The sensing part of the device consists of a field effect transistor with a suspended gate directly performed above the fluidic channel. Chemicals under test are driven through the sensing area between the electrical channel of the FET and the suspended gate. By this way products that flow in the microfluidic channel directly module the concentration of charges inside the transistor's gap and thus induce changes in the transfer characteristic. This paper describes the fabrication process and the technological choices for materials. Electrical tests, performed in air and in liquid, have shown a good behavior of the transistor, linked to a good mechanical sustain of the fluidic channel. The system is able to detect transition between air and liquid media. Moreover, it has shown a high sensitivity (about $300 \mathrm{mV} / \mathrm{pH}$ ) to $\mathrm{pH}$ measurements.
\end{abstract}

Keywords: pH sensor, microfluidic, Field effect transistor.

\section{INTRODUCTION}

Chemical sensors are important tools used in medicine for diagnostic, in chemistry for $\mathrm{pH}$ measurement and also in environmental monitoring for gas detection in air or ionic concentrations in water. Among sensors processed by microtechnologies, different structures of transistors, since the work of Bergveld [1], have shown main interest for chemical sensing, as ISFET (Ion Sensitive Field-Effect Transistor) [2-6], Floating Gate FET [7] or Extended Gate FET (EGFET) [8-10]. For all these devices, the maximum pH sensitivity is limited to the Nerstian response $(59.5 \mathrm{mV} / \mathrm{pH}$ at room temperature) [11, 12]. SGFETs (Suspended Gate Field Effect Transistor) involving gates suspended at submicron distance have shown good properties in charges detection [13]. They have been used in $\mathrm{pH}$ measurement [13-15] and detection of biological species [16-18]. These original structures have shown impressive characteristics, in particular high detection sensitivity. This sensitivity has been demonstrated in the detection of $\mathrm{pH}$, but also biological detection (DNA, proteins) [16-18]. An analytical model devoted to these microsensors and based on the 2D-numerical resolution of Poisson's equation, has been developed [19]. The response of quasi-static $\mathrm{C}(\mathrm{V})$ plots versus $\mathrm{pH}$ is simulated using both electrolyte charge distribution and site-binding theory considering the influence of sites densities on silicon nitride. It has 
allowed to show that this specific geometry with a suspended gate at submicronic distance changes the charges distribution and leads to a high sensitivity to $\mathrm{pH}$, significantly greater than that obtained for structures of the same family as ISFET $[11,12,19]$.

Many of the chemical sensors are integrated in a microfluidic system, to improve the flow management and prevent from evaporation. In addition, this integration can reduce the required amount of liquid, which is especially valuable for biological materials that can be quite expensive or not readily available. The fabrication of a microfluidic system molded into PDMS (Polydimethylsiloxane) microchannel is the most used technique [20, 21]. It was also performed with SGFET [14], encapsulated in a PDMS micro-fluidic device to drive chemicals flow nearby the sensor. This integration helps the driving of liquid and is useful in rinsing steps, so that it become easy to define a precise and reproducible protocol of use. However, in the case of SGFET but also of other chemical sensors, the liquid chamber is often oversized compared to the scale of the sensor itself.

One solution is to integrate a microfluidic channel within field effect transistor in order to drive the liquid in the active area of the sensor. This new technology is harder to perform but give the advantage of an integrated microfluidic sensor easy to use and should increase the reliability of the detection.

This paper presents the technology that has been developed to process the structure as well as its applications, in particular for the measurement of $\mathrm{pH}$ with high sensitivity.

\section{TECHNOLOGY}

\subsection{General design}

The basic structure is a field effect transistor with an integrated microfluidic channel. The floor of the fluidic channel contains the drain, the source and also the electrically active area of the transistor, whereas the top of the fluidic channel corresponds to the gate of the transistor. The fluidic channel is insulated from the contacts of the device. The height of the fluidic channel can be easily fixed by monitoring the thickness of the different layers, especially the sacrificial one. Inlets and outlets, connected to the external fluidic system, can be made with PDMS.

The general structure is shown figure 1. Several transistors can be designed along one fluidic channel.

In this structure, the channel must be mechanically sustained on a long length. It is then necessary to use a layer with good mechanical and electrical properties, as this layer will act as gate and channel cover. Moreover, the sacrificial layer should be easy to etch.

\subsection{Microchannel fabrication}

The microchannel process is based on the use of a sacrificial layer and a structural layer. Two sacrificial materials have been investigated. The first one is a photoresist deposited by spin coating with a thickness of $1 \mu \mathrm{m}$. The second one is made of silicon dioxide deposited by Radio Frequency sputtering. These two materials have been chosen for their properties of deposition and etching. The first one limits the temperature for the end of the process as well as the temperature of use. The second one can be easily used in classical high temperature processes. For this, the optimization of the oxide layer, in order to obtain a particular high etch rate in $2 \% \mathrm{HF}$ solution (hydrofluoric acid) has been achieved by changing the pressure of deposition. A high wet etch rate of 1.1 
$\mu \mathrm{m} / \mathrm{min}$ is obtained. For the structural layer the materials used were either silicon nitride and polycrystalline silicon $(50 \mathrm{~nm} / 700 \mathrm{~nm})$ for substrates with oxide as sacrificial layer, or sputtering RF Silicon oxide deposited at room temperature and aluminium $(100 \mathrm{~nm} / 800 \mathrm{~nm})$ in case of photoresist as sacrificial layer. The process steps are shown figure 2 .

The last step consists to remove the sacrificial layer by using the two openings, which also will act as inlet and outlet.

Fig. 3 shows cross section of micro-channel using photoresist (figure 3.a) or silicon oxide (figure 3.b) as sacrificial layer. Etching of $750 \mu \mathrm{m}$ length by HF $2 \%$ for SiOx is very long and reacts with the most materials used. The photoresist is quickly etched by acetone which doesn't react with other materials. Thanks to these properties, the photoresist was chosen for use as sacrificial layer in the fabrication of sensor. As show figure 3 , the gate is suspended with good mechanical sustain.

\subsection{Technological process for the sensors}

Sensors have been processed on silicon wafers by surface micromachining associated to classical high temperature MOS process. Substrates used are $\mathrm{Si}\langle 100\rangle$ oriented and low doped (N type). The drain and source are doped by boron diffusion at $1100^{\circ} \mathrm{C}$. The protection layer is a $1,2 \mu \mathrm{m}$ thick $\mathrm{SiO}_{2}$ film. The channel is then oxidized at $1100^{\circ} \mathrm{C}$ to obtain a $70 \mathrm{~nm}$ thick layer. This step is followed by a LPCVD deposit (Low Pressure Chemical Vapor Deposition) of a $100 \mathrm{~nm}$ thick layer of silicon nitride, which acts as sensitive layer to the $\mathrm{H}_{3} \mathrm{O}^{+}$ ions.

Then, a $1 \mu \mathrm{m}$ thick photoresist S1818 sacrificial layer is deposited by spin-coating, followed by a $100 \mathrm{~nm}$ thick $\mathrm{SiO}_{2}$ layer deposition by radio frequency sputtering at room temperature, performing thus the insulating layer for the bottom of the suspended gate. Via are opened in this insulating layer (silicon nitride and silicon dioxide) to reach source and drain contacts.

Gate and drain source contacts are then obtained by the deposition of a $1 \mu \mathrm{m}$ thick aluminium layer. A final $100 \mu \mathrm{m}$ thick layer of SU8 photoresist is deposited by spin coating to protect the aluminium and also, thanks to its elastic properties, to protect the gate from mechanical stresses. A scheme of P-type FET with microfluidic channel is presented in figure 4 at the step before removing the sacrificial layer.

Finally, after removal of the sacrificial layer, PDMS (Polydimethylsiloxane) inlet and outlet can be added on the openings (fig 3).

\section{EXPERIMENT AND RESULTS}

\subsection{Characterization in air}

FETs with microfluidic channel have been characterized to show the good behaviour of these devices. Devices are first tested before and after the etching of the sacrificial layer. One example of transfer characteristics is given figure 6 . 
It is shown in this figure, from the difference between the two characteristics, that the sacrificial layer has been successfully removed. Indeed, the capacitance $C_{I}$ between the gate and the electrical channel has changes as well has the conductance and the current between source and drain.

The model of classical MOS transistor can then be used. The current $\mathrm{I}_{\mathrm{DS}}$ in the linear regime $\left(\left|V_{D S}\right|<<\left|V_{G S}-V_{T}\right|\right)$ is expressed by:

$$
\left|I_{D S}\right|=\frac{W}{L} \mu C_{I}\left[\left|\left(V_{G S}-V_{T}\right) V_{D S}\right|-\frac{V_{D S}^{2}}{2}\right]
$$

With $\mathrm{W}$ and $\mathrm{L}$ the width and the length of the transistor, $\mu$ the carrier mobility and $\mathrm{V}_{\mathrm{T}}$ the threshold voltage.

The following figure illustrates the output characteristic of FET with integrated microfluidic channel measured in air. The characteristic shows good modulation of drain current by the gate voltage that as in usual field effect transistors.

\subsection{Detection of liquids}

The change in transfer characteristic of the transistor with air in the channel and water in the channel is clearly shown in figure 8 . The conductance increases when the water is injected, and is linked to an increase of the permittivity between the gate and the electrical channel leading to an increase of the insulator capacitance $\mathrm{C}_{\mathrm{I}}$.

Another measurement used to highlight the water injection is based on sampling test. The transistor is biased with a constant gate voltage of -11 Volts and a drain source voltage of -4 volts. The drain source current $\left(I_{D S}\right)$ increases widely when liquid reach the transistor channel area. Once the channel is filled with water the drain current $I_{D S}$ remains stable and constant. It also could be noticed that the gate current $I_{g}$ is weak showing the good electrical insulation.

\subsection{PH sensing}

FETs with integrated microchannel have been tested with solutions of different $\mathrm{pH}$ values. Basic solutions have been produced with $\mathrm{NaOH}$ and acid solution by using boric acid. Drain-source currents $\mathrm{I}_{\mathrm{DS}}$ have been measured versus the gate voltage $\mathrm{V}_{\mathrm{GS}}$, with drain-source voltage $\mathrm{V}_{\mathrm{DS}}$ fixed at $-2 \mathrm{~V}$. Figure 10 shows the transfer characteristics with different $\mathrm{pH}$ values tested at ambient temperature. The threshold voltage decreases for higher $\mathrm{pH}$ values, which is the correct behaviour of a traditional FET $\mathrm{pH}$-meter. This phenomenon is explained by the decrease in the amount of positives ions $\mathrm{H}^{+}$and increasing the amount of negative ions $\mathrm{OH}^{-}$in the test solution when the $\mathrm{pH}$ increases, inducing more negative charges at the surface of the transistor channel. Each measurement is made on static operation mode. The devices are tested in the $\mathrm{pH}$ range from 5 to 10 which is the interesting range for targeted applications, as $\mathrm{pH}$ variations in physiological liquids, or $\mathrm{pH}$ control in water for environment applications. Extreme $\mathrm{pH}$ values could be measured by adding a protecting layer on the surface of the sensor thus improving its insulation.

The $\mathrm{pH}$ sensitivity is defined as the gate voltage variations per $\mathrm{pH}$ unit for fixed drain-source current $\mathrm{I}_{\mathrm{DS}}$. The variation of $\mathrm{V}_{\mathrm{GS}}$ with $\mathrm{pH}$ is reported for different $\mathrm{pH}$ values and different devices in figure 11. This variation of voltage is calculated from the $\mathrm{V}_{\mathrm{G} 0}$ value, given for a $\mathrm{pH}$ equal to 7 . This curve is quite linear and the sensitivity 
calculated from the slope is $290 \mathrm{mV} / \mathrm{pH}$. This high value that exceeds the Nernst sensitivity obtained with ISFET sensors was also obtained with suspended gate FETs.

The electronic transducer, which is a field effect transistor, has a short response time, less than one second. The response time of the chemical sensor will be higher, and is especially due to the relaxation time of chemical elements, their interaction with the surface and the time for the liquid to reach the sensing area. As the device is more complex than the ISFET structure, the response time will be higher than the one for ISFET but could be improved by optimizing the design of the microchannel. By the way, the major interest of the new sensor is its high sensitivity to $\mathrm{pH}$ compared to classical ISFET sensors.

\section{CONCLUSION}

Microfluidic channels of $1 \mu \mathrm{m}$ height and $200 \mu \mathrm{m}$ width have been processed by surface micromachining using a simple method of sacrificial layer patterning. The top of this channel acts also as a gate performing by this way a FET with an integrated microfluidic channel. The integration of transistor inside this microchannel has been quite successful. Indeed, first, the structure shown good mechanical sustain after sacrificial layer removal, and thus prove the feasibility of the concept. Second, electrical tests have shown the good functioning of FETs with integrated fluidic channel and especially a good stability after removal of the sacrificial layer.

Tests with liquids have shown a quite promising sensitivity to different $\mathrm{pH}$. In next experiments microfluidic inlet and outlet and the design of microfluidic channels will be improved because it is still a weak point of the device especially to facilitate the liquid injection in the small dimension channel. 


\section{REFERENCES}

[1] P. Bergveld, "Development of an ion sensitive solid-state device for neuro-physiological measurements", IEEE Trans. Biomed. Eng.17 (1970), 70-71.

[2] J. Janata, “20 years of Ion selective Field Effect Transistors”, Analyst 1994, 119, 2275-2278.

[3] A. Errachid, J. Bausells, N. Jaffrezic-Renault, "A simple REFET for pH detection in differential mode", Sensors and Actuators B: Chemical 60 (1) (1999), 43-48.

[4] P. Bergveld, "Thirty years of ISFETOLOGY - what happened in the past 30 years and what may happen in the next 30 years", Sensor Actuat B-Chem 2003, 88:1-20.

[5] C. Jimenez-Jorquera, J. Orozco, A. Baldi, “ISFET Based Microsensors for Environmental Monitoring”, Sensors 2010, $10,61-83$.

[6] I. Humenyuk, B. Torbiero, S. Assie-Souleille, R. Colin, X. Dollat, B. Franc, A. Martinez, P. Temple-Boyer, “Development of pNH4-ISFETs Microsensors for Water Analysis”, Microelectron. J. 2006, 37, (6), 475-479.

[7] Shi Zhaoxia, Zhu Dazhong, "Modeling and discussion of threshold voltage for a multi-floating gate FET pH sensor", Journal of Semiconductors Vol. 30, No. 11 November 2009

[8] L. L. Chi, J. C. Chou, W. Y. Chung, T. P. Sun, S. K. Hsiung, "Study on extended gate field effect transistor with tin oxide sensing membrane”, Mater ,Chem Phys 2000;63:19-23.

[9] Y.L. Chin, J.-C. Chou, Z.C. Lei, T.-P. Sun, W.Y. Chung, S.-K. Hsiung, "Titanium nitride membrane application to the extended gate field effect transistor pH sensor using VLSI technology”, Jpn. J. Appl. Phys. 40 (2001) 6411-6415.

[10] P. D. Batista, M. Mulato, “ZnO extended-gate field-effect transistors as pH sensors”, Appl Phys Lett 2005;87:143508.

[11] D. E. Yates, S. Levine, T. W. Healy, “Site-binding model of the electrical double layer at the oxide/water interface”, J Chem Soc Faraday Trans I, 1974, 70: 1808. 
[12] J. Janata, "Electrochemistry of chemically sensitive field effect transistors", Sensors and Actuators, 4 (1983), 255-265.

[13] T. Mohammed-Brahim, A-C. Salaün, F. Le Bihan, "SGFET as charge sensor: application to chemical and biological species detection", Sensor\& Transducers journal, 900, (2008) 11-26.

[14] A. Kherrat, F. Le Bihan, F. Razan, N. Coulon, L. Griscom, O. De Sagazan, S. Crand, T. Mohammed-Brahim "pH Micro-Sensors Associated with Micro-Fluidics for Chemical Analysis”, ECS Transactions, vol. 33, Issue 8, Chemical Sensors 9, (2010) 153-159.

[15] B. da Silva Rodrigues, O. De Sagazan, S. Crand, T. Mohammed-Brahim, N. Morimoto, "pH meter based in Suspended Gate Field Effect Transistors to application in monitoring of water quality", ECS Transactions, vol. 39, Issue 1, Optoelectronics and Sensors, (2011) 291-298.

[16] De Sagazan O., Harnois M., Girard A., Le Bihan F., Salaun A.C., Crand S., Mohammed-Brahim T., "Direct Electrical Detection of Biological Species", ECS Transactions vol. 14, Microelectronics Technology and Devices, Issue 1, pp. 3-10, 2008.

[17] A. Girard, O. De Sagazan, F. Le Bihan, , T. Mohammed-Brahim, F. Geneste, P. Brissot, C. Guguen-Guillouzo, «Electrical Detection of very low content of transferrin in view of iron metabolism characterization", ICST 2008, International Conference on Sensing Technology, Tainan, Taiwan, November 30 to December 3, 2008, proc pp. 637-641.

[18] M. Harnois, O. De Sagazan, A-C. Salaün, T. Mohammed-Brahim, S. Bezieau, "Electronic Detection of Genetic Mutation Using Suspended-Gate Transistor: Application to Clinical Diagnostic”, proceeding p1.108, Biosensors 2008, Shanghai, Chine, 14-16 Mai 2008.

[19] A.-C. Salaün, F. Le Bihan, T. Mohammed-Brahim, "Modeling the high pH sensitivity of Suspended Gate Field Effect Transistor (SGFET)”, Sensors and Actuators B, 158 (2011) 138-143, 2011.

[20] X. M. Zhao, Y.N Xia, G. M. Whitesides, “Soft lithographic methods for nano-fabrication.”, Journal of Materials Chemistry 7, 1069-1074 (1997).

[21] G. M. Whitesides, E. Ostuni, S. Takayama, X. Jiang, D. E. Ingber. "Soft lithography in biology and biochemistry", Annual Review of Biomedical Engineering 3, 335-373 (2001). 


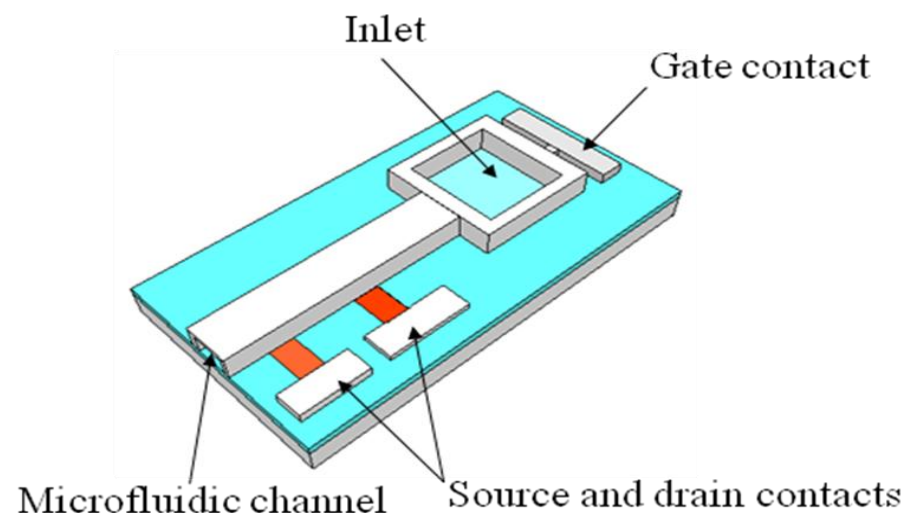

Figure 1. 

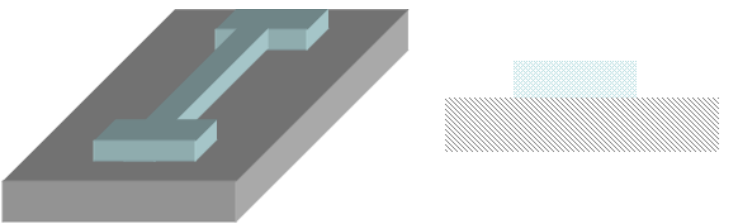

substrate

sacrificial layer

structural layer

a) Deposition of sacrificial layer

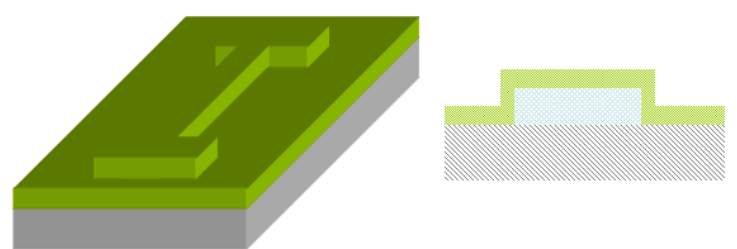

b) Deposition of structural layer
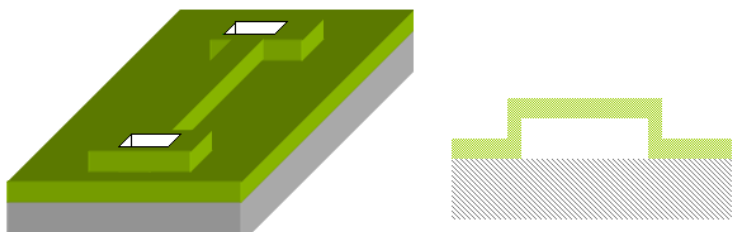

c) Creating openings (inlet, outlet) and releasing the channel

Figure 2. 

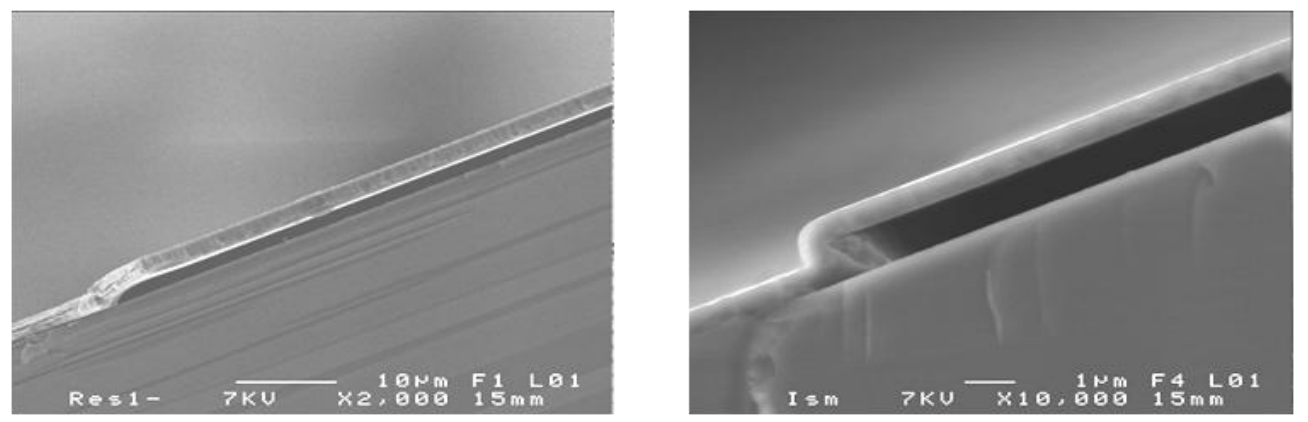

Figure 3 


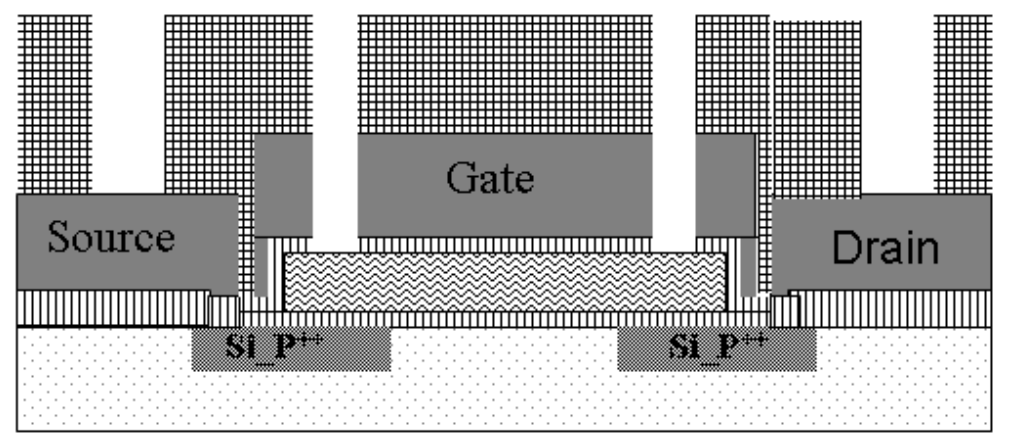

典曲 SU8

$\square$ Aluminium

盂耑 $\mathrm{SiO}_{2}$

Sacrificial layer

Figure 4 


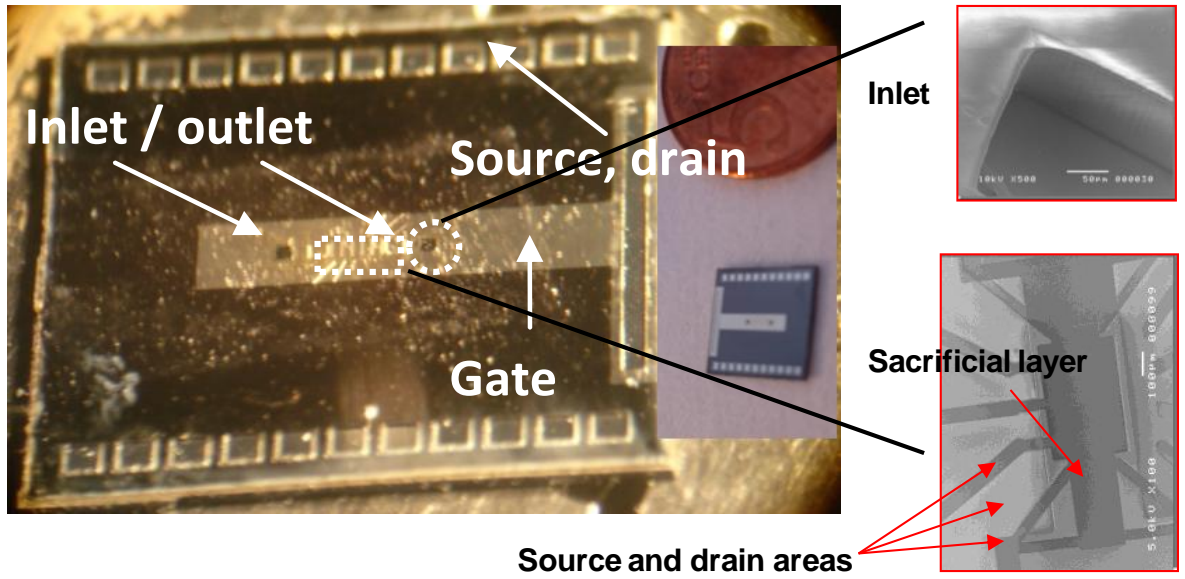

Figure 5 


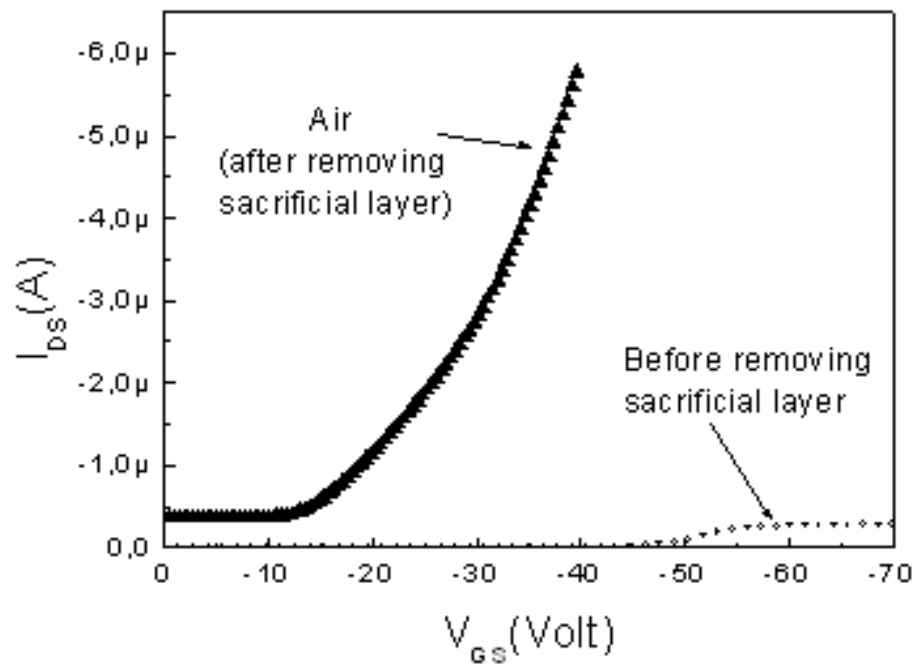

Figure 6. 


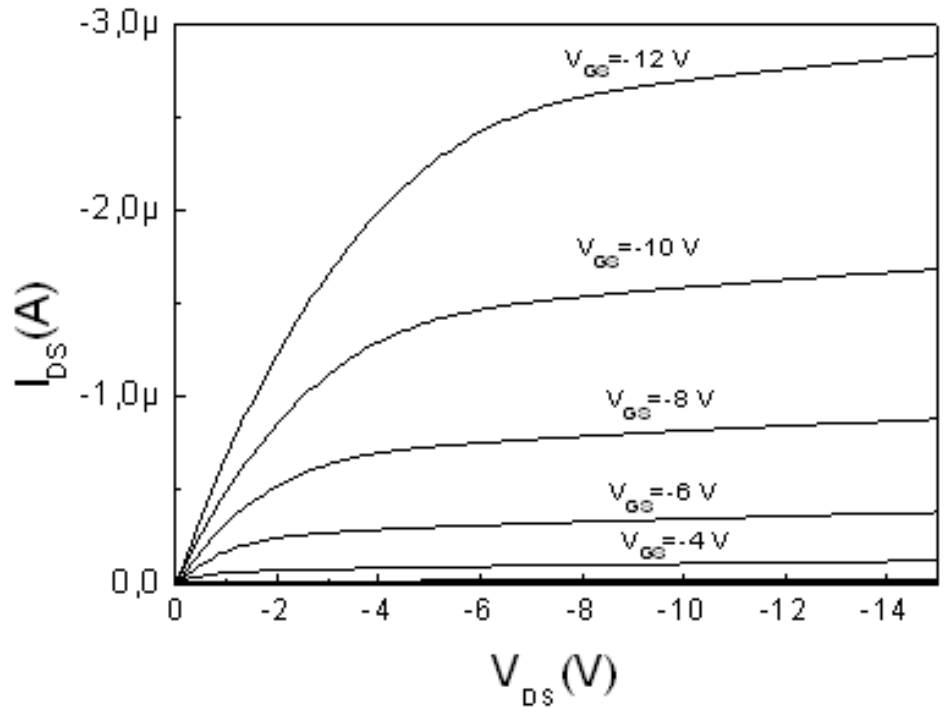

Figure 7 


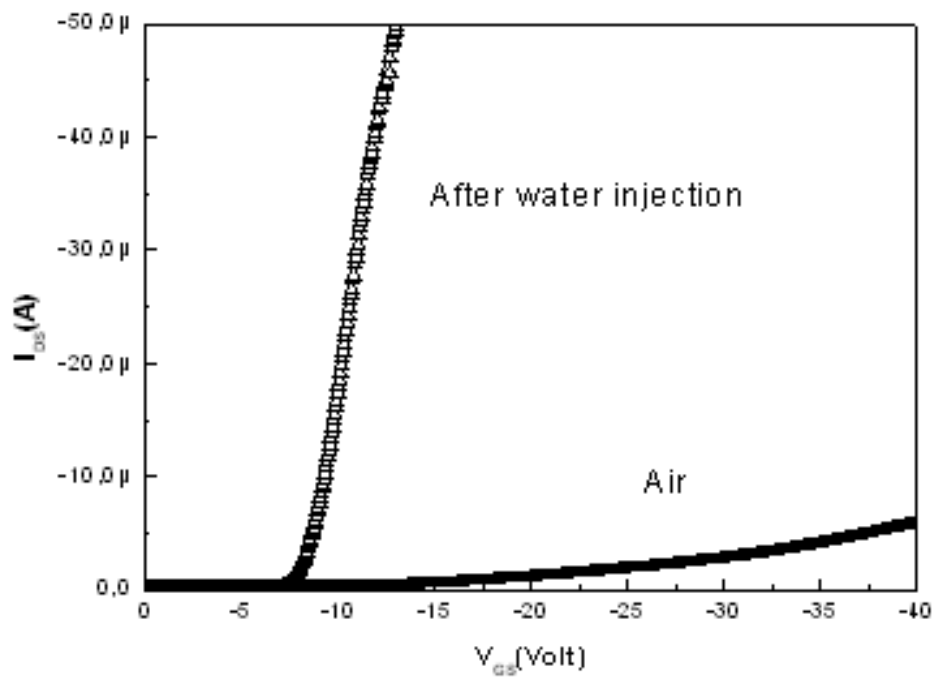

Figure 8 


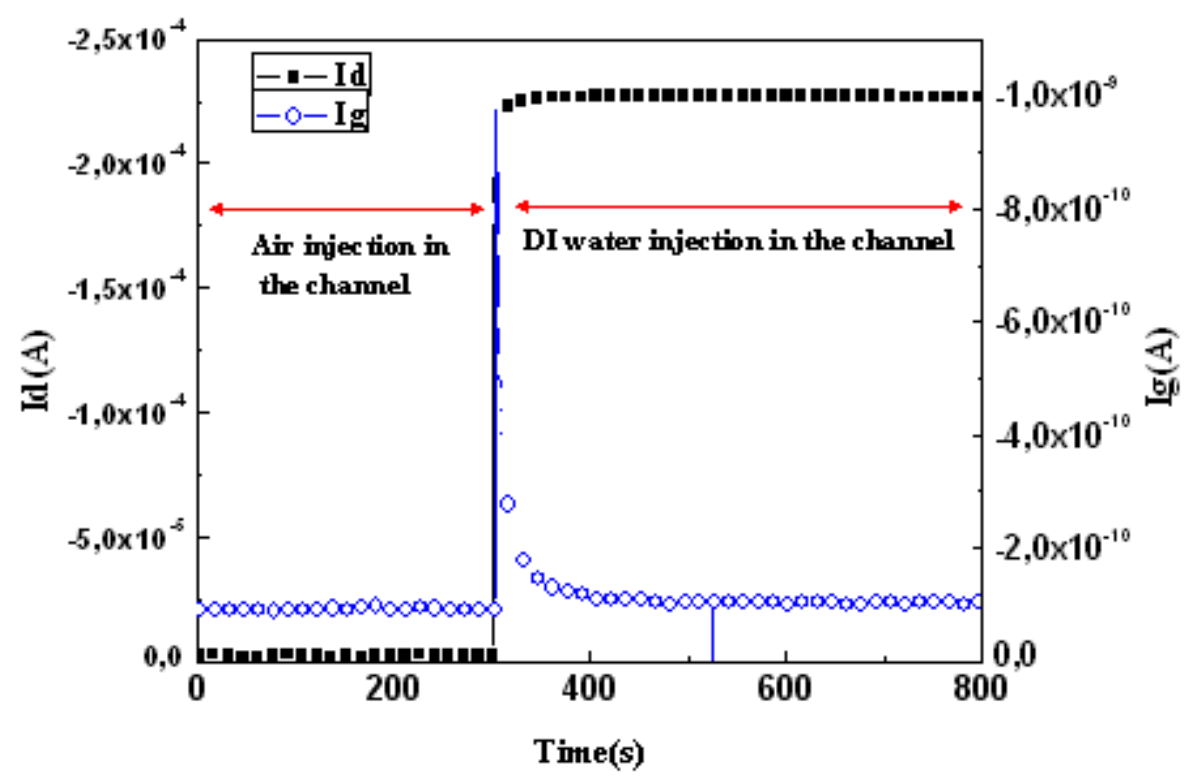

Figure 9 


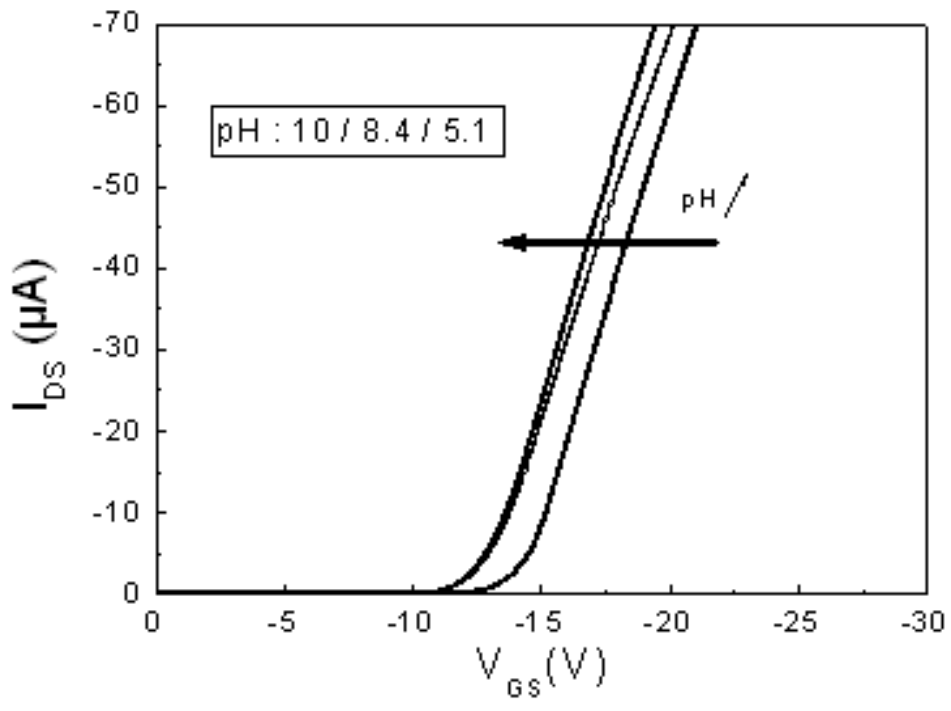

Figure 10 


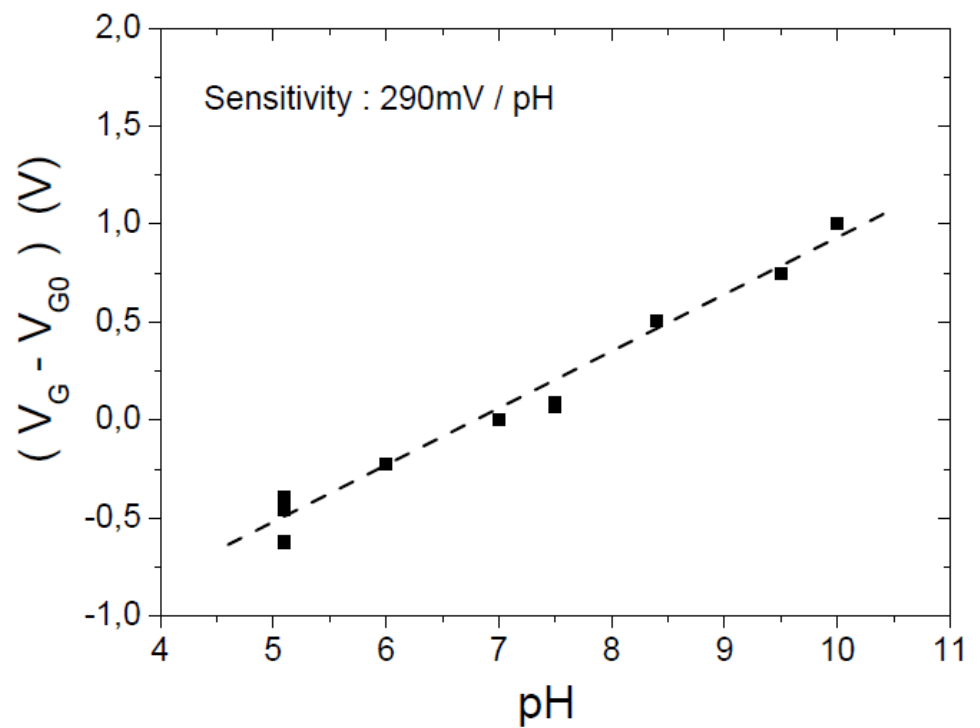

Figure 11 


\section{List of captions :}

Figure 1: Schematic structure of FET with fluidic microchannel.

Figure 2: Steps for the manufacturing of microchannel.

Figure 3: SEM cross-section showing the micro-fluidic channel: (a) Using photoresist as sacrificial layer, (b) Using SiOx as sacrificial layer.

Figure 4: Cross section showing the device before removal of sacrificial layer.

Figure 5: (a) Optical picture showing the design of the aluminium gate under a SU8 layer, inlet and outlet are visible on both side of the channel, (b) SEM picture showing the SU8 protection of the device and the inlet, (c) design of doped p-wells crossing the channel area is zoomed.

Figure 6: Transfer characteristics before and after the etching of the sacrificial layer $\left(\right.$ for $\left.V_{D S}=-2 \mathrm{~V}\right)$.

Figure 7: Output characteristics of FET with integrated microfluidic channelafter the removing of the sacrificial layer.

Figure 8: Transfer characteristic of the FET with air or water in the fluidic channel.

Figure 9: Drain current $\left(I_{D S}\right)$ sampling showing the two operating ranges in air and DI water. Transition is direct and level of current to stable.

Figure 10: Electrical transfer characteristic with different $\mathrm{pH}$ values.

Figure 11: Plot of the gate voltage variations versus $p H$ at fixed drain source current. 